\title{
USO DO SOLO E DINÂMICA DE CONFLITOS, NA BACIA DO RIO DOS SINOS - MUNICÍPIOS DE CAMPO BOM, NOVO HAMBURGO E SÃO LEOPOLDO, RS, BRASIL.
}

\author{
Luis Eduardo Robaina; Adriano Severo Figueró e \\ Sandro Sidnei Vargas de Cristo \\ Departamento de Geociências - CCNE \\ UFSM - Santa Maria, RS
}

\section{ABSTRACT}

The regional occupation has its origin dating back to the start of German immigration. The European settlers that arrived from the state of Rio Grande do Sul brought with them relatively more advance production techniques. Thus, there was rapid regional economic growth, based on agricultural products supplying Porto Alegre, the state's capital city. Capital accumulation in the region brought about industrialization which was also linked to the development of cattle raising activities due to abundance of laborpower and related raw materals. Urban occupation was divided in three categories, according to their intensity: high, medium and low as determined by building patterns, urban equipment and available services Non-urban areas are considered as being latent urban development grounds. Both the small 
farms used primarily for leisure activities and those with some agricultural and cattle raising activities seem to have little future.

\section{RESUMO}

A ocupação na região de estudo, está associada à forma como se estruturou a imigração alemã no Estado do RS. Os europeus vindos para o Rio Grande do Sul, possuíam técnicas de produção trazidas de sua origem, que proporcionaram o início à agricultura comercial. No período que sucedeu à chegada dos imigrantes, ocorreu um rápido crescimento econômico da região, baseado na atividade agrícola que abastecia a cidade de Porto Alegre. Isso originou um acúmulo de capital que propiciou o início das atividades industriais. O processo de industrialização esteve ligado ao desenvolvimento da agropecuária devido à existência de um mercado interno que dispunha de mão-de-obra e abundante matéria prima. O desenvolvimento das operações industriais e o conseqüente aprofundamento das relações capitalistas, estabeleceram as bases de um modelo regional socialmente excludente e insustentável do ponto de vista ambiental, motivo pelo qual se intensifica a dinâmica dos conflitos no âmbito da área estudada. O principal objetivo foi delimitar as diferentes formas de uso do solo presentes na região, identificando-se os conflitos delas decorrentes, com especial interesse nas formas de ocupação do espaço urbano e suas conseqüências. Nas áreas de uso tipicamente urbano, foram identificados 3 padrões de ocupação nitidamente diferenciados, definidos como alto, médio e baixo, conforme os indicadores estabelecidos (padrões de edificação, condições de infra-estrutura e serviços disponíveis). As áreas que não cumprem funções tipicamente urbanas foram consideradas como reservas de valor possíveis de serem incorporadas pelo mercado imobiliário. As chácaras de lazer e as áreas voltadas à produção agropecuária parecem refletir uma situação transitória na região. 


\section{INTRODUÇÃO}

O uso do solo é aqui entendido como as diversas formas de intervenção do homem no meio, visando atender às suas necessidades. 0 uso do solo é, dessa forma, um dos principais indicadores dos níveis de troca que se estabelecem nas relações sociedade/natureza, sendo a sua análise de vital importância para o entendimento da estrutura e da dinâmica ambiental de um espaço qualquer. O levantamento do uso do solo consiste no mapeamento e avaliação quantitativa e qualitativa de tudo que existe sobre a superfície do terreno. A análise do uso da terra é fundamental, a fim que se possa diagnosticar e planejar uma forma mais adequada e racional de ocupação do solo.

A área de estudo conta com 35380,5 ha, representando uma das regiões do Estado do Rio Grande do Sul com maior número de atividades industriais e com elevada ocupação urbana. Localizada no Vale do Rio do Sinos, constitui a porção de terra sob influência do Rio dos Sinos, entre o arroio Campo Bom e o Canal João Corrêa. Está limitada geograficamente pelas coordenadas: $29^{\circ} 50^{\prime}$ e $29^{\circ} 36^{\prime}$ de latitude Sul e $51^{\circ} 12^{\prime}$ e $50^{\circ} 57^{\prime}$ de longitude Oeste, abrangendo parte dos municípios de Campo Bom, Novo Hamburgo e São Leopoldo (Figura 1).

\section{METODOLOGIA}

Para o levantamento do uso e ocupação do solo, analisou-se a evolução histórica da ocupação e do processo de urbanização na região, através de estudos bibliográficos e pesquisa junto ao Museu Histórico Visconde de São Leopoldo e a Câmara Municipal de São Leopoldo. A identificação dos padrões e a elaboração da carta de uso e ocupação do solo, foram desenvolvidas por meio de perfis de campo apoiados com GPS e reconhecimento aéreo feito com o apoio do Aeroclube de São Leopoldo. No detalhamento das áreas urbanas, contou-se com a utilização de mapas 
municipais confeccionados pelas prefeituras (São Leopoldo,1991 na escala 1: 10.000, Planta do Plano Diretor da Cidade de Campo Bom , 1994 na escala 1:10.000 e Novo Hamburgo, 1991 na escala 1: 15.000).

Para a realização do trabalho, foram identificadas três classes principais de uso do solo: áreas de campo e agricultura, mata e área urbana. $\mathrm{Na}$ categoria de "área urbana", a análise dos padrões de edificação, das condições de infra-estrutura e dos serviços disponíveis, permitiram classificar as referidas áreas em 3 padrões de ocupação: alto, médio e baixo padrão.

Posteriormente ao mapeamento das classes de uso do solo, passou-se à identificação dos agentes e relações que se estabelecem na dinâmica dos conflitos gerados pelas diferentes formas de ocupação do espaço.

\section{DESENVOLVIMENTO URBANO/INDUSTRIAL DA REGIÃO}

A rápida urbanização e crescimento das cidades, especialmente no último século, mudou a fisionomia da Terra mais do que qualquer outra atividade humana em toda a história.

No final do século XVIII teve início a Revolução Industrial na Europa, fruto da grande acumulação de capitais por parte das metrópoles. Nessa época, a industrialização passou a ter influência no aumento das taxas de urbanização gerando, por conseqüência, uma redefinição dos padrões espaciais então vigentes. Os países capitalistas e industrializados começaram a dominar a economia mundial. Esta incipiente indústria tinha nas aglomerações urbanas as condições necessárias ao seu desenvolvimento. O desenvolvimento das indústrias impulsionou o crescimento acelerado das cidades pela necessidade de concentração espacial da mão-de-obra, indispensável às fábricas, e condição fundamental à reprodução do capital (OLIVEN, 1984). 
Conforme SANTOS (1996), o capital encontra no meio urbano os elementos indispensáveis (força-de-trabalho) para sua ampliação e extração da mais-valia. A cidade como área de concentração da força de trabalho, aparece como uma ilustração da espacialidade do capitalismo, onde uma pequena parcela da população apropria-se da maior parte da produção social, tornando-se dona dos meios de produção, ocupando áreas privilegiadas da cidade. Em outra parte, significativa parcela da sociedade, reduzida à condição de classe assalariada, sujeita-se a ocupar locais de moradia distantes e com deficiência de infra-estrutura. A exclusão social passa a ser refletida pela exclusão espacial das áreas urbanas, modelo este que se consagrou ao ser extrapolado para todas as áreas sob influêncla da lógica capitalista.

Vinculada à espacialidade da exclusão social, a crise ambiental passa a ser gestada e reproduzida no interior das áreas urbanas, decretando definitivamente a falência do projeto iluminista de progresso que não consegue envolver a todos (CAVALCANTI,1997).

$\mathrm{Na}$ região de estudo, o período após a chegada dos colonos alemães foi marcado por um rápido crescimento econômico, com a produção agrícola em poucos anos florescendo, a ponto de permitir que a colônia passasse a abastecer a capital, Porto Alegre.

O primeiro pólo de desenvolvimento foi dado pelas vias fluviais, que permitiam o contato das colônias com Porto Alegre. A penetração ao longo do rio dos Sinos e afluentes, oportunizava o estabelecimento de fazendas, inicialmente nas zonas planas, posteriormente também nas regiões montanhosas.

Um importante registro que deve ser feito na análise do processo de ocupação que está diretamente associado à industrialização do Vale dos Sinos, é que ao lado do trabalho agrícola, os alemães também eram "Handwerker", isto é, artesãos, trabalhavam a madeira, o ferro, o couro e as fibras. Desse artesanato, na Alemanha, provieram muitos nomes próprios, 
como: Schmidt que significa ferreiro; Schuster, sapateiro; também Schuhmacher, sapateiro; Weber, tecelão; Zimmermann, carpinteiro; Schreiner, marceneiro; Schneider, alfaiate; Wagner, construtor de carroças; Muller, moleiro (PORTO, 1934). Com seu trabalho os artesãos formaram as bases da industrialização no Rio Grande do Sul. Não é para menos que o Vale dos Sinos transformou-se numa extraordinária concentração industrial. Muitas grandes fábricas espalhadas pelas cidades de origem alemã começaram com um verdadeiro artesanato, em pequenas casinhas de porta e janela, onde tudo era feito a mão.

Por outro lado, o processo de industrialização ligado ao curtimento de couro, esteve associado ao desenvolvimento da agropecuária pela existência de um mercado interno, de mão de obra , abundante matéria prima (couro) e de capital.

Segundo dados históricos apresentados pelo IBGE (1959), já no ano de 1829, Luiz Rau estabeleceu o primeiro curtume e, seguindo seu exemplo, outros sete colonos dedicaram-se à indústria do couro, dando início ao processo de industrialização efetivo. Em 1830 João Pedro Schmidt adquiriu a casa de negócio de Luiz Kersting e deu grande impulso ao comércio de Hamburgo Velho, comprando os produtos agrícolas de toda a zona colonial e revendendo-os em Porto Alegre, para onde eram transportados em lanchões. A construção da primeira estrada de ferro no RS, ligando Porto Alegre a Hamburger Berg, foi um marco importante para o desenvolvimento da região (LANDO \& BARROS, 1981). O estabelecimento da ligação ferroviária canalizou para o comércio da região quase toda a produção local, sendo um fator de grande importância para a estruturação de um mercado interno que iria sustentar a futura industrialização. Nesta mesma época, o Sr. Pedro Adams Filho iniciou a produção e o comércio de calçados, em bases modernas, ao mesmo tempo que o Sr. Arthur Haas dava impulso à produção de artigos de couro (IBGE, 1959). Essas indústrias, já exploradas a 
muito, porém em reduzida escala, se desenvolveram rapidamente, despertando também em outros setores a iniciativa.

\section{CARACTERIZAÇÃO DO USO E OCUPAÇÃO ATUAL DO SOLO}

A bacia hidrográfica do Rio dos Sinos, abrange uma importante área do Estado do Rio Grande do Sul, em vista da população residente e da riqueza gerada no território por ela banhado. Entretanto, a interferência humana nas formas de uso do solo têm trazido conseqüências danosas aos recursos hídricos da região, uma vez que, historicamente, não houve preocupação em harmonizar o desenvolvimento econômico e social com a conservação do meio ambiente ${ }^{1}$.

Junto ao crescente deslocamento da população para os centros urbanos, houve um acirramento da concentração de riquezas e de terras e uma degradação do meio ambiente e da qualidade de vida da população. As cidades vão tendo as suas áreas progressivamente ocupadas de uma forma desordenada, reduzindo significativamente a qualidade de vida. As camadas mais empobrecidas da população não têm outra opção senão a de ocupar áreas de fundo de vales, margens de drenagens, encostas íngremes, enfim, os espaços possíveis, rejeitados pela burguesia.

A região teve, em especial nas décadas de 70 e 80 , um grande desenvolvimento econômico. Entretanto, esse desenvolvimento, da forma que está concebido não promove benefícios que aliviem a pobreza e ampliem a qualidade de vida. Tampouco um planejamento rígido e tecnocrata, desvinculando o social, garantirá crescimento sadio para a cidade como um todo.

Nos últimos vinte anos a população da região quase dobrou, puxado pela indústria calçadista e metalúrgica, aumentando o

\footnotetext{
1 Obviamente, não se poderia esperar que o fruto de uma desigualdade social fosse uma relação harmoniosa da sociedade com a natureza

Rev. Ciência e Natura, Santa Maria, 21: 119 - 137 , 1999. 
desenvolvimento de loteamentos populares. Hoje, o problema social está agravado pela crise que passa o setor calçadista e, consequentemente, o desemprego causado, o que constitui um fator ainda maior de pressão ao meio ambiente.

As análises dos censos demográficos do IBGE, juntamente com informações das Prefeituras da região, permitem observar muito claramente esse situação. Desde sua emancipação (1959) até hoje, a população do município de Campo Bom duplicou e atingindo em cheio a área social, que ganhou oito loteamentos populares, sem infra-estrutura com mais de 1000 famílias. O fechamento de várias fábricas de calçados agravou ainda mais o problema, uma vez que causou o desemprego de milhares de sapateiros nos últimos anos. O mesmo se deu com os municípios de São Leopoldo e Novo Hamburgo, Em São Leopoldo, os últimos 20 anos resultaram em 120 loteamentos irregulares. Novo Hamburgo inchou do dia para a noite. No início dos anos 70, a cidade tinha cerca de 60 mil habitantes; duas décadas e meia depois, este número cresceu mais de três vezes.

Diferentes funções acarretam variadas demandas na dinâmica espacial do município. Com base nisso, na elaboração do presente trabalho dividiu-se a área estudada em duas categorias principais: espaços com função urbana e espaços com função não urbana.

Dentro da categoria de uso urbano, foram identificados três padrões de ocupação diferenciados, definidos em função das características das construções, infra-estrutura e serviços disponíveis (Tabela 1). A ocorrência destes diferentes padrões de ocupação, resulta em graus diferenciados de exposição aos processos de degradação ambiental. Os riscos geológicos e as catástrofes naturais são tão maiores quanto menores os cuidados iniciais com o meio ambiente. Resultam, principalmente, do processo de ocupação marcado pelo acesso diferenciado ao espaço urbano e não apenas das causas naturais, as quais, no entanto, não podem ser negligenciadas. 
É possivel perceber desta forma, que o estado da paisagem depende basicamente de dois elementos: o nível de estabilidade natural da paisagem (representada pelo equilíbrio interno dos seus elementos e que varia de uma paisagem para outra) e os tipos e graus de impacto a que esta paisagem pode ser submetida. $\mathrm{O}$ cruzamento destes dois elementos nos dá o grau de sensibilidade ou vulnerabilidade ambiental da paisagem. Neste sentido, para este estudo trabalhou-se com três classes de vulnerabilidade, associadas diretamente ao padrão de ocupação.

Da mesma forma que nas demais regiões que apresentam um processo dinâmico de acumulação do capital, as regiões urbanas da bacia do rio dos Sinos apresentam uma correlação direta entre o padrão de ocupação e o grau de vulnerabilidade ambiental. Quando da ocorrência de fortes chuvas, os problemas aparecem, em especial, nas áreas menos nobres. As populações mais pobres, além de não terem condições econômicas de desenvolverem obras de contenção, ocupam as áreas mais vulneráveis.

\subsection{Definição dos padrões de ocupação no espaço urbano}

Os espaços com função urbana foram divididos em três padrões diferenciados de ocupação: Alto, Médio e Baixo padrão, distribuídos conforme a Figura 2.

As áreas consideradas de alto padrão estão representadas por atividades comerciais diversificadas, com serviços permanentes e edificações construídas em sua maioria com materiais de construção de boa qualidade, acabamento concluído e infra-estrutura completa. O arruamento é planejado e a taxa de impermeabilização do solo é bastante alta.

As áreas de médio padrão ocorrem em locais com densidade de ocupação média/alta, apresentando ainda alguns vazios urbanos e infraestrutura e equipamentos restritos. As construções são, na sua maioria, com as mesmas características da anterior (Figura 3). Representam áreas mais periféricas, constituindo bairros afastados do centro. 
Nas ocupações definidas como de Baixo Padrão, as moradias são de precário acabamento, a população tem baixa renda e os arruamentos não são planejados (Figuras 4 e 5). Em geral a taxa de impermeabilização do solo é bem inferior a das áreas anteriores e não dispõem de controle do escoamento das águas pluviais e servidas. Na fase de implantação de loteamentos, os solos são expostos à erosão. A implantação parcial da infraestrutura (drenagem e pavimentação), somada à concentração e o lançamento de águas da chuva e servidas, favorecem a ocorrência de processos erosivos. Ocorre também o assoreamento das drenagens por resíduos urbanos (lixo, materiais de construção, etc.), além de inundações e problemas de saneamento. Ocorrem junto a planície de inundação do Rio dos Sinos, nas margens dos arroios e, também, junto a encosta, ao Norte da área.

As áreas caracterizadas como de predomínio de funções não urbanas, correspondem às regiões com baixa densidade ocupacional, onde predomina o uso extensivo do solo, especialmente ligado às atividades agropecuárias. Para estas regiões foram definidos dois tipos diferenciados de uso: de um lado as áreas com cobertura vegetal arbórea mais ou menos degradada, que inclui as áreas com vegetação natural e áreas de reflorestamento; de outro lado, as áreas não florestadas, compreendendo as áreas agrícolas, áreas de campos e banhados. A distribuição destas classes na área de estudo aparece representada na figura 2.

A classe de florestas compreende as áreas cobertas principalmente por mata e capoeira (Figura 6). Muito embora esta classe apareça, também, em alguns espaços restritos da área urbana, onde o relevo é mais enérgico ou onde se definem áreas de preservação ela não executa uma função tipicamente urbana, ou seja, não está diretamente ligada à produção econômica ou às formas de reprodução do capital.

Desde a colonização a região têm sofrido uma contínua e crescente devastação das matas nativas, devido à implantação de culturas, 
extração de arenitos em grande escala e extração da madeira. As áreas de reflorestamento representam uma recomposição da cobertura florestal já devastada, em sua maioria para fins econômicos, com monocultura de espécies exóticas como eucalipto, pinus e acácia-negra.

As áreas onde predomina a vegetação herbácea, intercalada por arbustos e árvores esparsas, localizam-se próximas às áreas rurais ou de expansão urbana. As áreas agrícolas (Figura 7), são destinadas principalmente a cultivos perenes ou temporários (ciclo estabelecido). Nas áreas urbanas destacam-se a horticultura e as chácaras rurais (que destinam parte dos lotes a pequenos cultivos). Nestas áreas, há a possibilidade de surgirem, ou mesmo agravarem-se os processos erosivos, quando os solos são expostos.

Restaram nas margens do Rio dos Sinos, poucos banhados nos quais ainda resta vegetação natural, por constituírem áreas de difícil acesso e por estarem sujeitas às inundações periódicas. São refúgio da fauna silvestre, viveiro natural de peixes e aves, ainda auxiliando como reguladores do regime hídrico do rio e como filtros biológicos das águas. Dentre estes, destaca-se o Banhado da Avenida Imperatriz Leopoldina, que tem grande extensão em área contínua (bem mais de 500 ha) e a vegetação está razoavelmente preservada na baixa de domínio das cheias, havendo ainda resíduos da vegetação arbórea nos terraços junto ao rio, e raros, mas valiosos, sobreviventes nas adjacências. O banhado de Campo Bom, situado entre $29^{\circ} 44^{\prime}$ a $29^{\circ} 41^{\prime}$ e $51^{\circ} 00^{\prime}$ a $51^{\circ} 06^{\prime}$, sem dúvida nenhuma, constitui uma área ecológica de enorme importância na grande Porto Alegre e para o Vale do Rio dos Sinos.

\section{CONSIDERAÇÕES FINAIS}

A cidade como área de concentração da força de trabalho, reflete na sua espacialidade a lógica do capitalismo, onde os trabalhadores 
que não detém os meios de produção estão sujeitos a ocupar locais distantes, deficientes de infra-estrutura e com problemas relacionados a ação intensa de processos ambientais. Isso está representado na divisão dos padrões de ocupação urbana na bacia do rio dos Sinos. As áreas de baixo padrão urbano tendem a representar zonas mais fragilizadas e que estão mais expostas a riscos ambientais, como inundações, escorregamentos, poluição e contaminação das águas e solos. As áreas de alto padrão, ao contrário, não estão sujeitas a riscos e por sinal incrementam a ação dos processos geológicos a jusante, pela grande impermeabilização do solo.

As áreas com vegetação natural, mais ou menos, preservadas que ocorrem nas regiões elevadas, no Norte e no extremo Sul da área de estudo, têm passado a sofrer uma valorização, através de uma propaganda que utiliza o discurso da qualidade ambiental. Atualmente, os condomínios fechados estão ocupando os espaços dos morros, especialmente no compartimento de relevo identificado como a região de transição ao Planalto (Figura 8). A especulação imobiliária intensa já se faz sentir com as empresas investidoras apresentando a paisagem com matas e vista agradável dos vales como argumento para a venda, ou seja, patrimônios de domínio público transformando-se em mercadoria de alta valorização. Parece claro que, muitas áreas usadas hoje como chácaras de lazer ou para a produção agropecuária, refletem uma situação transitória. Estes imóveis têm grande chance de passarem a parcelamentos ou desmembramentos que passarão a ser incorporados à malha urbana. 


\section{BIBLIOGRAFIAS}

CAVALCANTI, A.P.B. Desenvolvimento sustentável e planejamento. Fortaleza: UFCE, 1997.

IBGE. INSTITUTO BRASILEIRO DE GEOGRAFIA E ESTATÍSTICA. Enciclopédia dos Municípios Brasileiros. IBGE, V. XXXIV, Rio Grande do Sul, P-Z. Rio de Janeiro, 1959, 411p.

LANDO, Aldair M. \& BARROS, Eliane C. (1982). A colonização Alemã no Rio Grande do Sul, uma interpretação sociológica. Porto Alegre, 2ed., Movimento, 96p.

MACEDO, R.K. Gestão ambiental. Os instrumentos básicos para a gestão ambiental de territórios e unidades produtivas. Rio de Janeiro: ABES, 1994.

OLIVEN, Ruben G. (1984). Urbanização e Mudança Social no Brasil. Petrópolis, 3Ed., VOZES, 136p.

PORTO, Aurélio. (1934) Trabalho Alemão no Rio Grande do Sul. Estabelecimento Gráfico Santa Terezinha, Porto Alegre, 274p.

SANTOS, Milton (1996). A Urbanização Brasileira. 3Ed., São Paulo, HUCITEC, 157p.

TAUK-TORNISIELO, S.M. (org.) Análise ambiental: estratégias e ações. São Paulo: T.A. Queiroz, 1995. 
Tabela 1. Formas de uso e ocupação do solo e processos do meio físico.

\begin{tabular}{|c|c|c|}
\hline $\begin{array}{l}\text { Formas de uso e } \\
\text { ocupação }\end{array}$ & Características & $\begin{array}{l}\text { Problemas/Processos do } \\
\text { meio físico }\end{array}$ \\
\hline $\begin{array}{l}\text { Áreas com cobertura } \\
\text { vegetal arbórea (natural e } \\
\text { reflorestamento) }\end{array}$ & $\begin{array}{l}\text { Áreas com vegetação } \\
\text { natural em regiões restritas } \\
\text { onde o relevo é mais } \\
\text { movimentado; regiões de } \\
\text { recomposição vegetal para } \\
\text { fins econômicos }\end{array}$ & $\begin{array}{l}\text { Estas formas de uso } \\
\text { exercem ação protetora em } \\
\text { relação a processos de } \\
\text { movimento e transporte de } \\
\text { massa. }\end{array}$ \\
\hline $\begin{array}{l}\text { Áreas de uso para } \\
\text { campos e agrícolas }\end{array}$ & $\begin{array}{l}\text { Áreas destinadas a cultivos } \\
\text { perenes ou temporários ou } \\
\text { como pastagens }\end{array}$ & $\begin{array}{l}\text { Possibilidade de ocasionar } \\
\text { ou agravar processos } \\
\text { erosivos }\end{array}$ \\
\hline Banhados & $\begin{array}{l}\text { Áreas periodicamente } \\
\text { inundadas, com vegetação } \\
\text { característica }\end{array}$ & Inundações freqüentes \\
\hline $\begin{array}{l}\text { Áreas urbanas de médio } \\
\text { padrão }\end{array}$ & $\begin{array}{l}\text { Serviços e infra-estrutura } \\
\text { restrita }\end{array}$ & $\begin{array}{l}\text { Ação erosiva nas vias e } \\
\text { problemas de saneamento }\end{array}$ \\
\hline $\begin{array}{l}\text { Áreas urbanas de baixo } \\
\text { padrão }\end{array}$ & $\begin{array}{l}\text { Habitações precárias sem } \\
\text { infra-estrutura básica, junto } \\
\text { as margens de arroios, } \\
\text { banhados e encosta }\end{array}$ & $\begin{array}{l}\text { Movimentos de massa nas } \\
\text { encostas e poluição das } \\
\text { águas e inundações nas } \\
\text { baixadas }\end{array}$ \\
\hline $\begin{array}{l}\text { Área urbana de alto } \\
\text { padrão }\end{array}$ & $\begin{array}{l}\text { Em geral, material } \\
\text { construtivo de boa } \\
\text { qualidade e acabamento } \\
\text { concluído, rede de água e } \\
\text { esgoto, atividades de } \\
\text { serviços diversos }\end{array}$ & $\begin{array}{l}\text { Alta impermeabilização do } \\
\text { solo, elevado escoamento } \\
\text { superficial }\end{array}$ \\
\hline
\end{tabular}




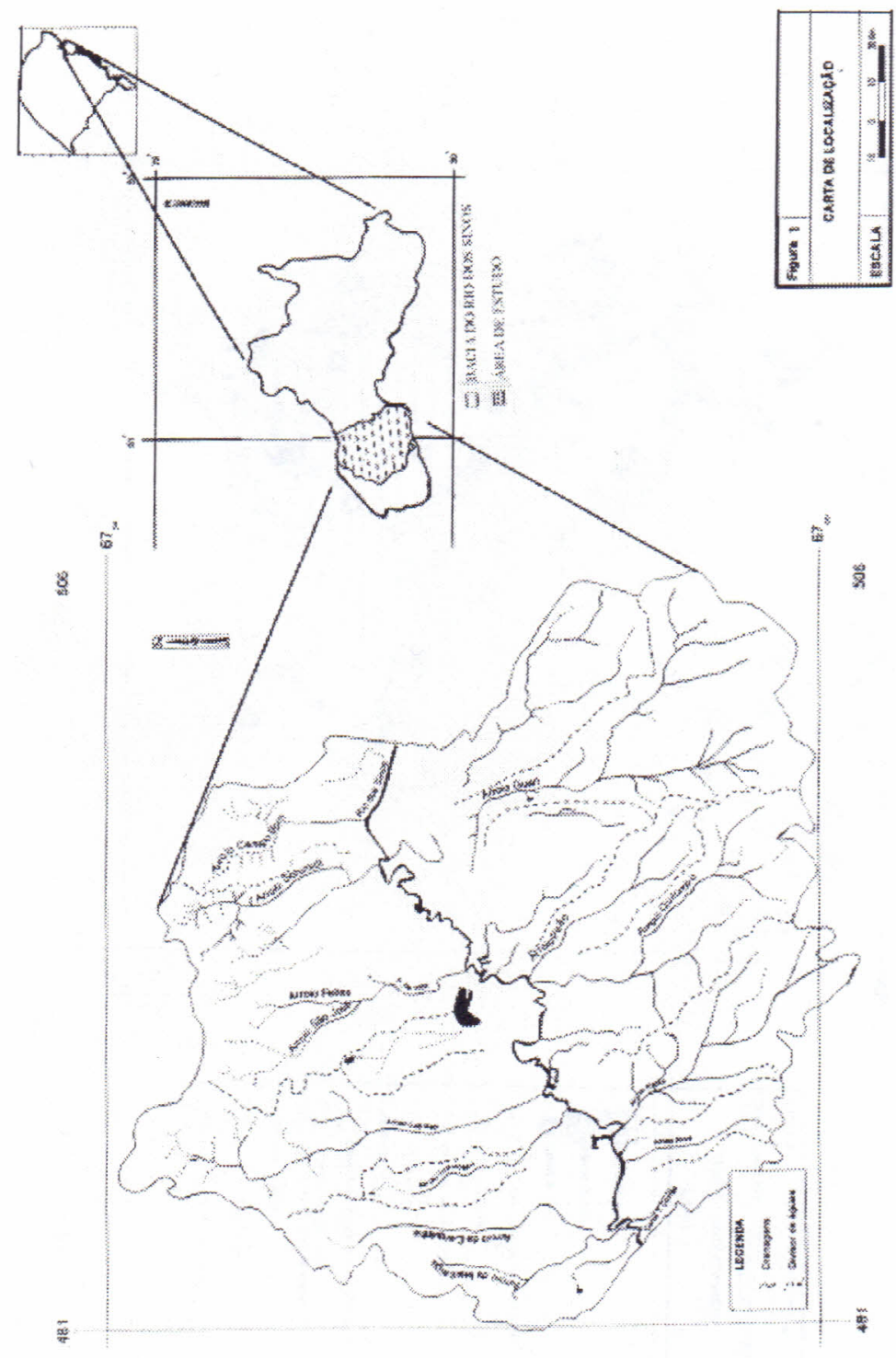

Rev. Ciência e Natura, Santa Maria, 21: 119 - $137,1999$. 

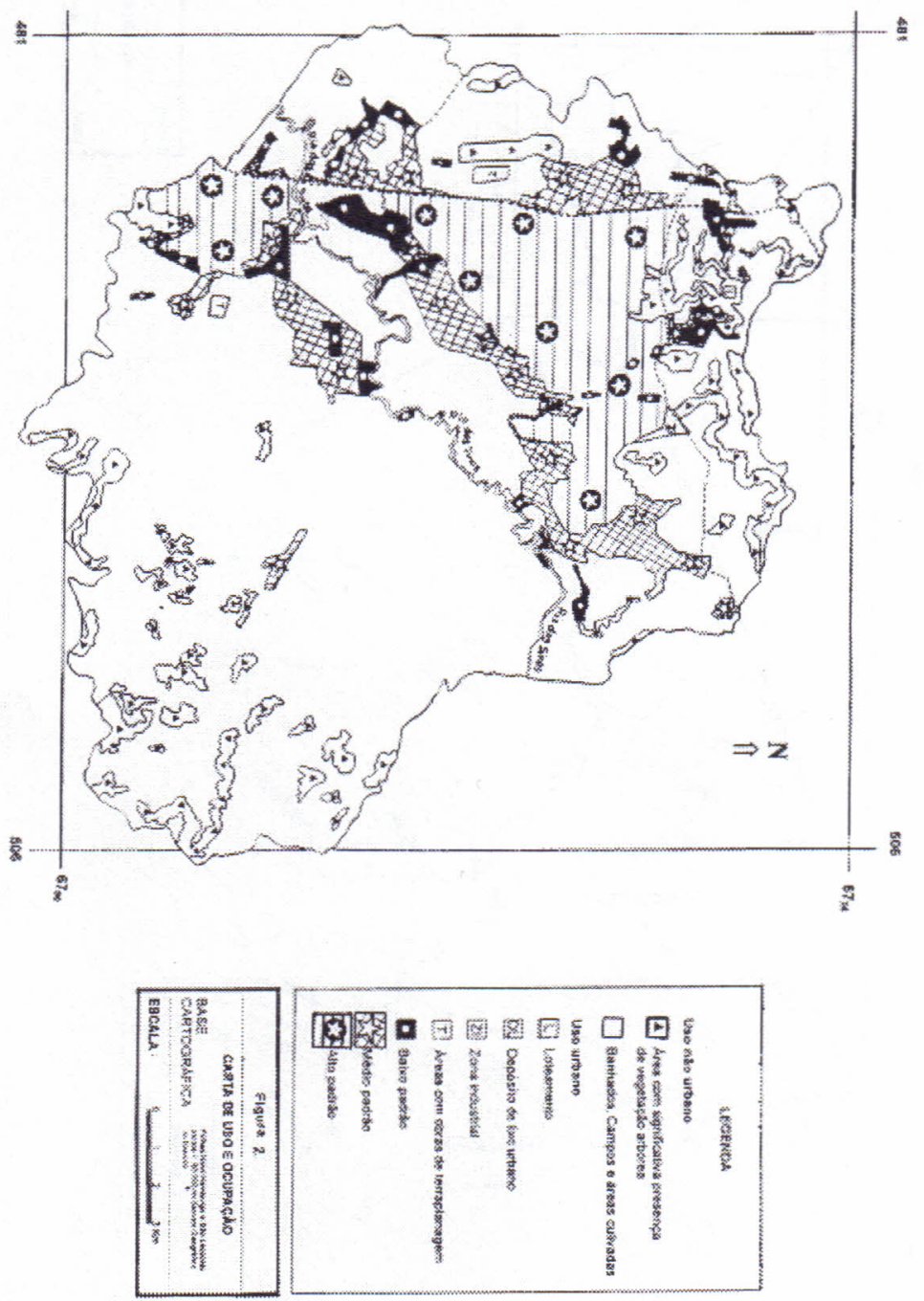

134 Rev. Ciência e Natura, Santa Maria, 21: 119 - $137 \quad, 1999$. 


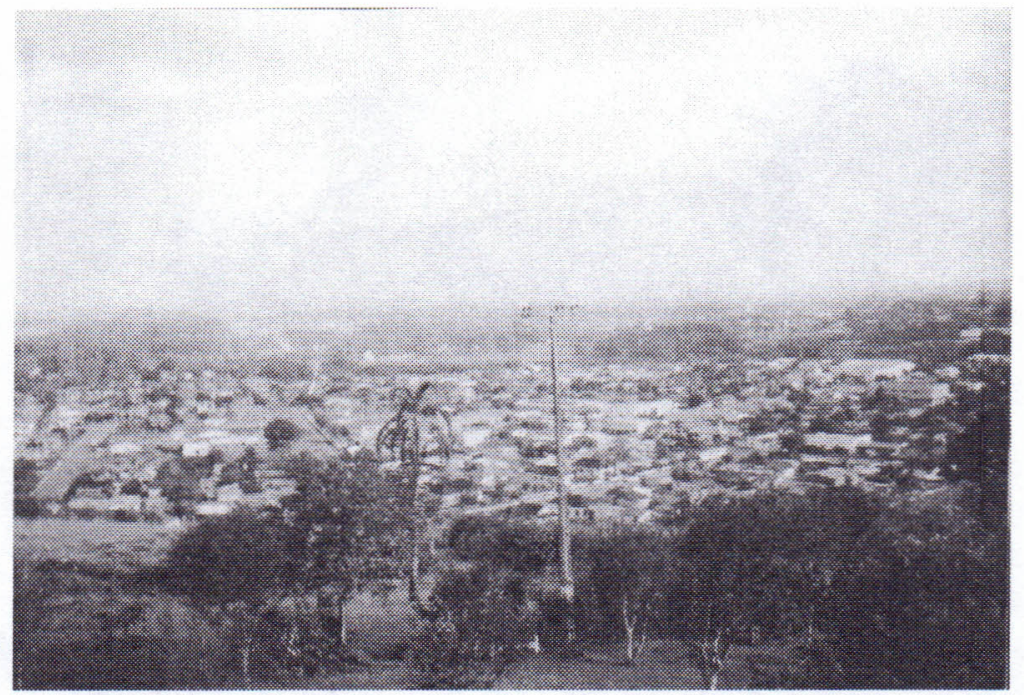

Figura 3. Vista de ocupação caracterizada como de médio padrão urbano. Área residencial no Município de Campo Bom (01/95).

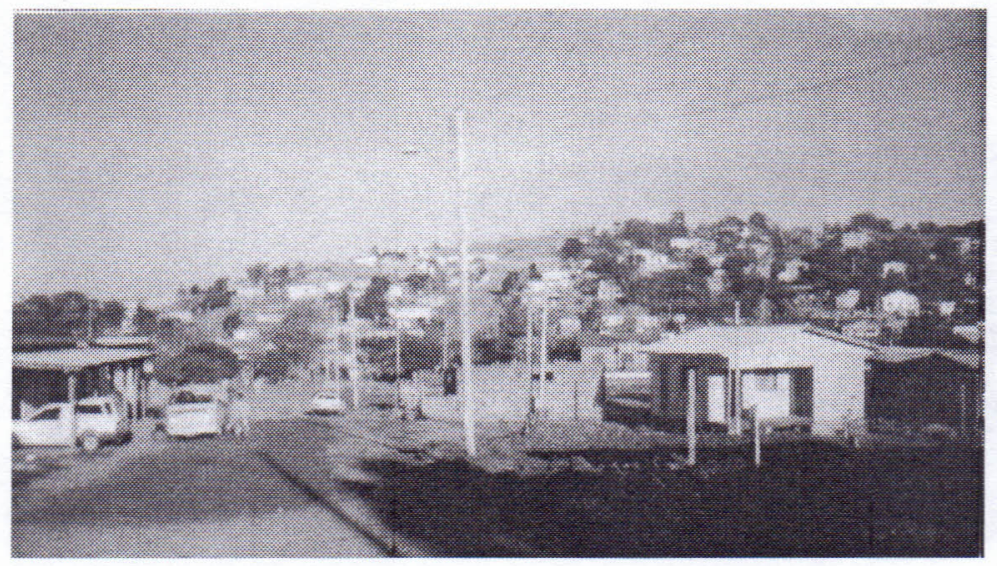

Figura 4.Área de baixo padrão urbano de ocupação - NW da cidade de Novo Hamburgo (01/95).

Rev. Ciência e Natura, Santa Maria, 21: 119 - 137 , 1999. 


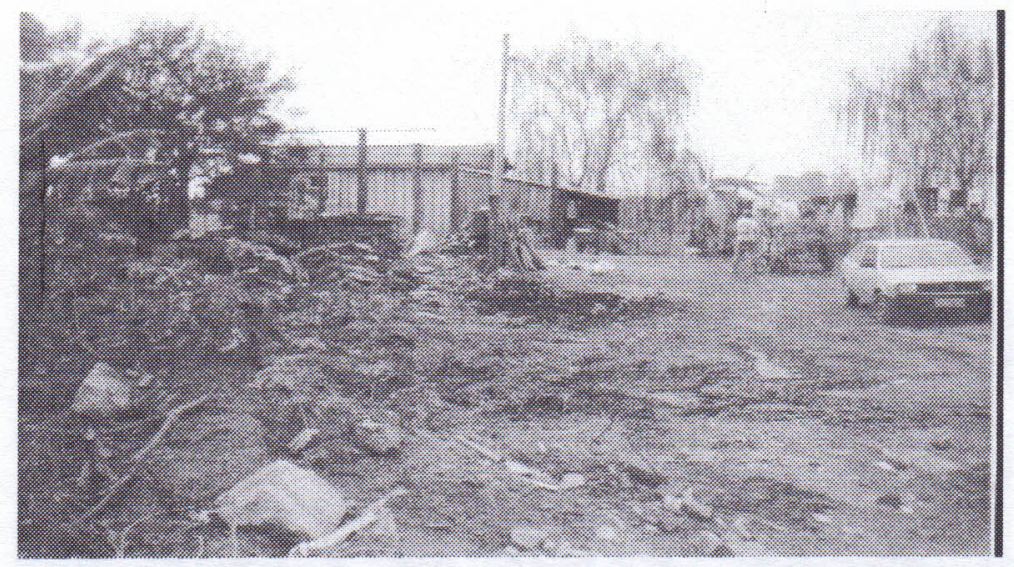

Figura 5.Ocupação de baixo padrão urbano, sobre a planície de inundação do Rio dos Sinos, São Leopoldo (01/95).

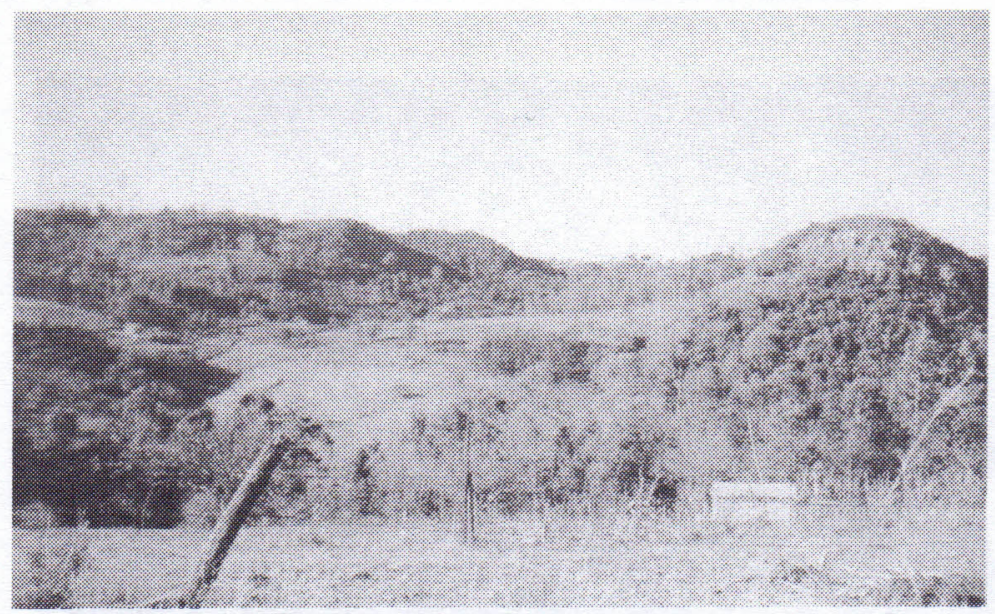

Figura 6. Áreas íngremes com vegetação natural e nas demais campos e cultivos Distrito de Lomba Grande - Novo Hamburgo (01/95). 


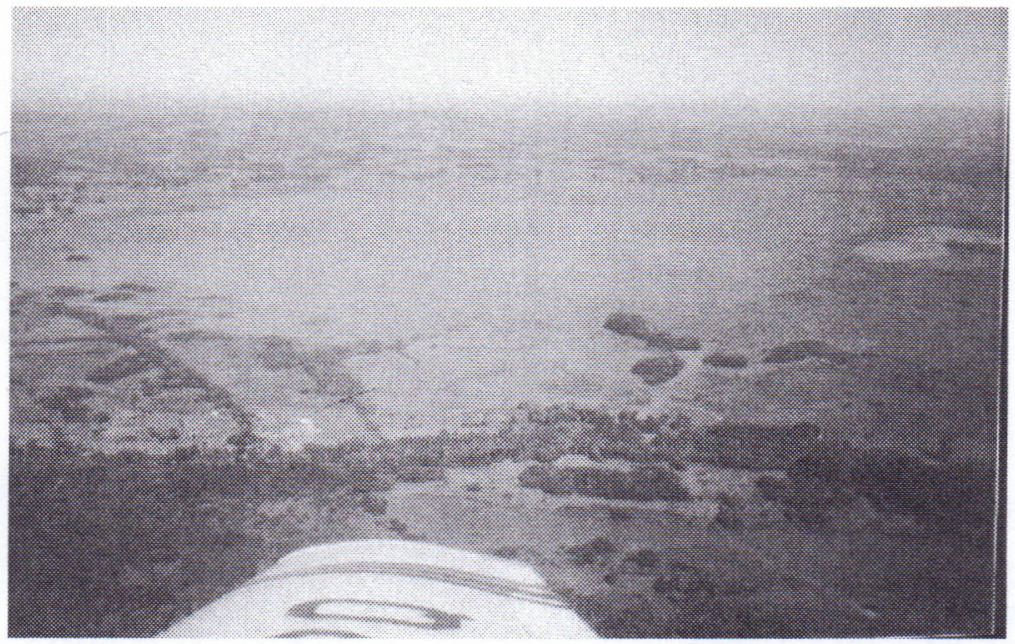

Figura 7.Área de banhado do Sinos com atividade agrícola (03/98).

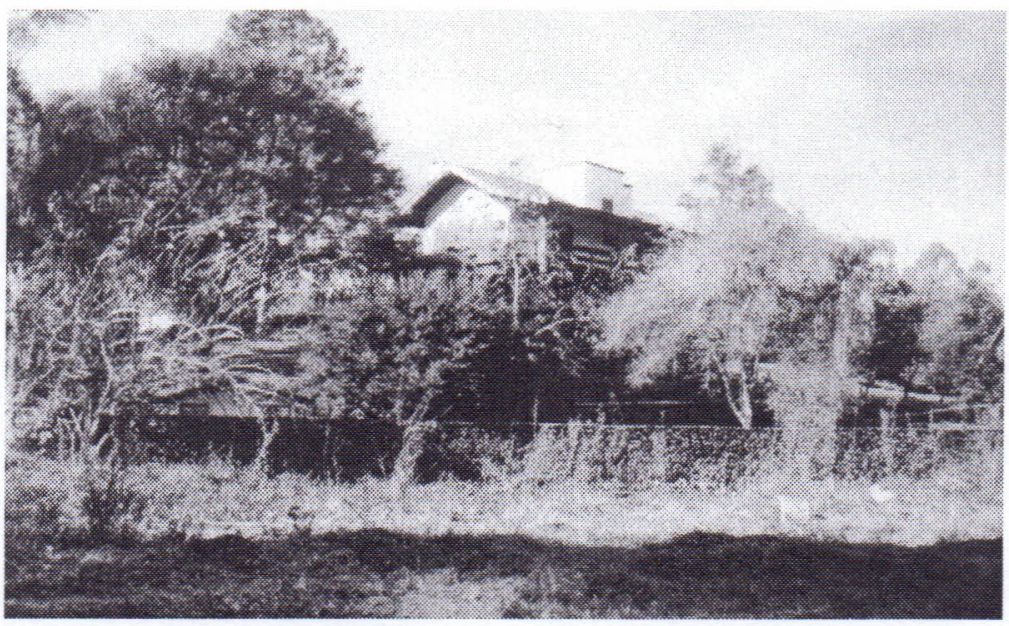

Figura 8.Condomínios fechados na área que sobe para o planalto em NovoHamburgo.

Rev. Ciência e Natura, Santa Maria, 21: 119 - $137 \quad, 1999$. 
